\title{
Educação sexual: contradições, limites e possibilidades
}

Cláudia Ramos de Souza Bonfim

Doutora em Filosofia e História da Educação pela Unicamp e Professora da Faculdade Dom Bosco de Cornélio Procópio/PR

\section{Resumo}

O presente estudo bibliográfico com aporte de campo, objetiva compreender as contradições, limites e possibilidades da Educação Sexual apresentada nas escolas, especialmente na disciplina de Ciências Biológicas. A análise pauta-se nas respostas dos docentes de Ciências e na história da sexualidade e da Educação Sexual Escolar no Brasil. Procura-se, fundamentar a necessidade da inserção de uma disciplina no currículo dos cursos de Licenciatura que aborde a construção histórica e cultural da sexualidade. Busca-se vislumbrar uma Educação Sexual que possibilite ao educando construir uma identidade crítica em meio à crise de valores éticos da sociedade.

Palavras-chave: Educação Sexual; Formação de Professores; Ciências Biológicas.

\begin{abstract}
This bibliographical study with input field aims to understand the contradictions, limits and possibilities of sex education provided in schools, especially in the discipline of Biological Sciences. The staff analysis on the responses of teachers of science and the history of sexuality and sexual education school in Brazil. Wanted, substantiate the need to insert a subject in the curriculum of courses of addressing the historical and cultural construction of sexuality. We seek to envision a sexual education that enables the learner build an identity criticism amid the crisis of ethical values in society
\end{abstract}

Key-words: Sex Education; Teacher Education; Biological Sciences. 


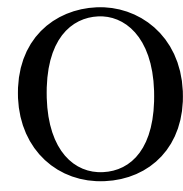

presente trabalho decorreu de nossa pesquisa de doutorado que teve por objetivo produzir um levantamento de critérios e diretrizes que possibilitasse conhecer, esclarecer e compreender as relações existentes entre a estrutura social e o sistema político brasileiro e suas influências históricas na construção da identidade e desenvolvimento da Educação Sexual Escolar no Brasil, especialmente na área de formação dos Licenciados em Ciências Biológicas. Buscando ainda, compreender as contradições, limites e possibilidades da Educação Sexual apresentada em nossas escolas, especialmente na disciplina de Ciências Biológicas, com o intuito de fomentar o debate em torno das questões epistemológicas do ensino de Ciências e Biologia, estimulando o debate sobre a Educação Sexual, reconhecendo a Biologia como um campo ou forma do agir humano e, portanto, produto histórico, fruto da conjunção de fatores sociais, políticos, econômicos, culturais e religiosos. Pautando-se nas respostas coletadas com docentes e na análise crítica da história da sexualidade humana, bem como da história da Educação Sexual Escolar no Brasil fundamentar a necessidade da inserção de uma disciplina na grade curricular dos cursos de licenciatura que aborde a construção social, histórica e cultural da sexualidade humana.

Acredita-se que um estudo histórico sobre a construção cultural da sexualidade humana pode ajudar a compreender os motivos políticos e sociais que levaram à sexualidade quantitativa e consumista que impera nos dias de hoje. E ainda, fomentar a reflexão crítica. Dependendo da forma como aborda as questões culturais a escola assume um caráter estratégico em sua compreensão.

Partiu-se do pressuposto da existência de uma Educação Sexual na escola, entretanto considerando necessário verificar qual é sua identidade, superando o conteúdo biológico que está sendo aprendido pelo aluno, articulando o conhecimento biológico ensinado com condicionantes históricos, culturais, políticos, sociais, éticos e estéticos da sociedade atual e ainda se os licenciados em Ciências Biológicas estão recebendo a formação na graduação para trabalhar a sexualidade. 
Os PCN’s e a inclusão da Orientação Sexual como tema transversal trazem para a escola a legitimidade para se dialogar sobre a sexualidade, mas segundo constatamos, os educadores não estão recebendo a formação adequada para desenvolver ações nesse sentido no curso de Licenciatura. Vemos uma contradição na inserção deste tema nos currículos escolares, porém, sem estar inserido no currículo dos cursos de Licenciatura.

A educação sexual apresentada na escola não deixa de ser relevante e informativa, através da apresentação da anatomia humana e dos métodos contraceptivos, mas não abordam claramente a sexualidade para além da condição biológica natural, que não pode ser negada, reprimida, isto seria negar a maturidade corporal do ser humano, seria delegar a educação sexual de nossas crianças e adolescentes à "mídia televisiva, fonográfica, cinematográfica, consumista, quantitativa, baseada em modelos estéticos da sociedade atual, em estereótipos" (Nunes, 1987, p.49), mas há de se ressaltar que a sexualidade é também uma construção cultural.

Vemos que a Sexualidade formal, meramente descritiva da escola tem tratado o tema sem articular e resgatar a concepção histórica e cultural, sem estabelecer uma teia com a vida real, sem refletir ética e esteticamente sobre os valores, tabus e padrões morais impostos pela sociedade. Em se tratando de doenças sexualmente transmissíveis, acreditamos que a questão é social e política.

Consideramos urgente que, enquanto educadores e pais, busquem nos aprofundar sobre a Educação Sexual, para então, agir da forma mais consciente e esclarecedora possível, contribuindo assim, para uma educação sexual emancipatória que prime pela liberdade, pela sensibilidade, pelo respeito e pela igualdade.

A formação do professor de Ciências Biológicas, assim como, os demais cursos de formação de professores, deveriam preparar o docente para estas questões, abrir debates e criar canais de significação para que sejam capazes de abordar a sexualidade de maneira plena, em todas as suas dimensões eróticas, subjetivas, procriativas e suas significações e consequiências com responsabilidade e autonomia e não apresentar uma 
identidade negativa e descritiva sobre o sexo e a sexualidade. Se nos esforçarmos para apresentar as razões de nossa determinação de compreender a sexualidade na trama da cultura e das relações sociais é justamente por acreditarmos que sua força humana e conseqüentemente pedagógica reside precisamente neste campo.

A educação sexual que pleiteamos não se resume tão somente a um amontoado de noções de biologia, prescrições médicas de higiene e informações anatômicas. Significa compreender o próprio ser do homem em suas bases mais exigentes, como natureza e cultura. Não que venhamos negar a fisiologia e a importância das determinações morfológicas naturais, campos que se traduzem em bases dos processos de significações culturais. A biologia, no entanto, tomada de forma reducionista, apresenta-se insuficiente para explicar nossas vivências sexuais, não conseguindo dar conta da amplitude de suas manifestações, que são historicamente constituídas. Há uma dificuldade muito grande em entender que o recurso à história é a chave da compreensão da sexualidade humana.

Os cursos de formação devem provocar e criar mudanças significativas na forma com os professores tratam e apresentam os conteúdos, inclusive contribuindo assim para a motivação dos alunos e da autonomia do professor. Considerando Nunes (1987) a formação de professores de Ciências Biológicas pauta-se ainda pelos critérios da Biologia descritiva e formal do século XIX, sem articular e resgatar a concepção histórica e cultural, sem estabelecer uma teia com realidade, sem refletir ética e esteticamente sobre os valores, as transformações do mundo do trabalho e as descobertas científicas, oferecendo, assim poucas possibilidades para que seus educandos possam mudar conscientemente e concretamente a conjuntura atual. Apresenta ainda, uma identidade naturalista, positivista distante dos atuais paradigmas de compreensão do mundo, anacrônica, defasada.

A Educação Sexual deve ultrapassar as concepções descritivas e vincular a ciência de uma dada época às demandas e pressões sociais que sobre ela são exercidas mais diretamente. Deve ser entendida como uma 
construção política, histórica, marcada pelas mudanças econômicas e estruturais da sociedade capitalista, como uma construção dinâmica, e cujos e impactos devem ser analisados epistemologicamente, eticamente e esteticamente, pois a ciência é um conjunto de conhecimentos que se desenvolvem, se acumulam, se transformam e se reestruturam em função de uma organização social.

É possível constatar que nas escolas e universidades, ainda hoje se ensina apenas anatomia descritiva, a divisão do corpo em "cabeça, tronco e membros", nomenclaturas, composições químicas e fórmulas. Apresentando uma visão a-histórica, desarticulada e ingênua, sem uma percepção crítica capaz de contribuir para sua superação. As Ciências Biológicas, assim como as demais ciências, estruturam-se conforme as orientações políticas e econômicas, através das transformações das bases materiais, da fundamentação valorativa dessas práticas derivadas das transformações no âmbito do trabalho.

Os conteúdos propostos pela maioria dos livros para o Ensino de Ciências sugerem uma notável ênfase na transmissão de conteúdos programáticos, quase sempre sem apresentar propostas de reflexão crítica sobre as problemáticas sociais, políticas e econômicas. Sendo assim, o aluno provavelmente aprenderá apenas a repetir o que aprendeu, sem estabelecer uma relação com seu cotidiano, sem compreender sua real significação. Vemos a necessidade de substituir essa concepção de ciências, baseada em taxonomias e nomenclaturas, por uma concepção de relacionar as problemáticas especialmente no que se refere ao meio ambiente, doenças e à sexualidade com as mudanças estruturais da sociedade em que vivem. Notamos que a preocupação maior dos professores é no sentido de cumprir o programa no tempo hábil, e não de estabelecer um programa que privilegie a formação emancipatória do educando.

Acreditamos, que a forma do ensino-aprendizagem no que se refere às Ciências Biológicas implícita nos livros didáticos e na forma do professor ministrar suas aulas têm raízes históricas que o condicionaram a trabalhar dessa forma, ou seja, uma deficiência em sua formação enquanto educador, 
infelizmente, ainda hoje, muitos professores acreditam que ensinar é transmitir informações e aprender seria memorizar e reproduzir as mesmas. Mudar essa concepção requer em nossa visão, uma reflexão filosófica, política e histórica sobre a Formação de Professores de Ciências Biológicas e das transformações estruturais no mundo do trabalho em face às mudanças do capitalismo globalizado.

Entendemos que para entender a sexualidade como está posta hoje, precisa-se compreender como estes modelos sexuais foram construídos historicamente, ou seja, como se entendeu e se entende a sexualidade humana, para isto, durante o estudo retornamos às matrizes conceituais e atuais sobre a Sexualidade Humana.

Nessa direção, entendemos que a Educação Sexual encontra-se ligada diretamente ao contexto histórico-cultural onde emerge e estrutura-se e, portanto, pretendemos no atual estudo, questionar as seguintes contradições:

$\mathrm{O}$ que os professores de Ciências do Ensino Fundamental entendem por Educação Sexual? Os mesmos se sentem aptos a discutir abertamente o tema de Educação Sexual, atendendo as expectativas dos alunos? Os docentes de Ciências Biológicas tiveram no seu curso de Licenciatura alguma disciplina referente à Sexualidade humana para além do conteúdo puramente biológico? Quais seriam as categorias epistemológicas e matrizes políticas dessas disciplinas? Como a Educação Sexual tem sido tratada e, quais as formas institucionais com que tem sido tratada nos cursos de Licenciatura em Ciências Biológicas e nas escolas públicas de ensino fundamental do Estado de Paraná?"

O universo delimitado para a efetivação da pesquisa de campo decorreu dos depoimentos coletados dos professores que atuam especificamente na $7^{\text {a }}$ série do Ensino Fundamental na disciplina de Ciências Biológicas das Escolas Públicas Estaduais que compõem o Núcleo Regional de Educação de Cornélio Procópio, Paraná. A escolha do lócus empírico da pesquisa de campo se deve por este ser o Estado em que esta pesquisadora nasceu, cresceu, obteve sua formação educacional e acadêmica, bem como por ser onde atua como docente em diversos níveis 
de ensino, dentre eles, como professora de ciências do ensino fundamental II seguimento, como orientadora educacional no ensino fundamental I seguimento e em cursos de Pós-Graduação Lato-sensu.

Consideramos que, são necessários estudos mais especializados que visem acompanhar o trabalho do professor, bem como repensar estratégias de capacitação profissional, no sentido de prepará-lo tecnicamente e politicamente para a sua função. Conforme Bernardo (1986), o preparo do corpo docente, tanto para si quanto para as escolas que ensinam crianças e adolescentes, é um campo, sem dúvida, concernente à competência universitária. O professor é um intelectual, cujo trabalho consiste em divulgar o saber ou, preferencialmente, mais do que isto, em elaborar os saber "com-os-outros". Essa particularidade impõe uma revisão da ação educativa na Universidade quanto à formação dos profissionais do ensino. Às Universidades e aos Órgãos relacionados à educação, cabe, ainda, a tarefa de estimular periodicamente pesquisas de perfil do campo de trabalho, a partir das quais se possa realizar projeções mais acertadas das perspectivas de absorção dos profissionais de licenciatura e bacharéis de Ciências Biológicas.

O estudo surgiu da necessidade de vislumbrar novos caminhos para a Educação Sexual apresentada no Ensino Fundamental na Disciplina de Ciências Biológicas, que possibilitem ao educando construir sua identidade em meio à crise de valores éticos que a sociedade globalizada e tecnológica vem sofrendo. Mudanças ocorrem também em relação aos padrões de comportamento, de representação da sexualidade, de consumo, de relações pessoais.

Entendemos que, uma determinada concepção de sexualidade e educação sexual prevaleceu como dominante na cultura conceitual das Ciências Biológicas e buscamos encetar um estudo que possa ir além da noção biologista-médica-higienista comumente aceita, como aponta Nunes (1996), superando-a por uma visão da construção histórica, política e cultural da sexualidade humana, mostrando suas potencialidades, sua totalidade, como expressão plena da identidade humana. Assim pretende-se 
contribuir para o debate da Educação Sexual na Escola pautado em uma filosofia da sexualidade, com uma base ética e estética, representada e vivida com responsabilidade afetiva, despida de reducionismos estreitos condicionados em sua construção social conservadora. Consideramos que uma Educação Sexual ética e estética é aquela investiga que valores estão embutidos ou expressos nas relações sexuais marcadamente condicionais pela visão falsamente moralista da sociedade capitalista, e que busca uma reflexão capaz de superar, elevar e humanizar a relação.

A complexidade de desenvolvimento real do tema da Educação Sexual parece indicar uma deficiência na forma como os professores têm sido formados nas universidades em suas respectivas licenciaturas ou espaço de formação inicial. Em nossa pesquisa, pudemos constatar especialmente nos cursos de Licenciatura em Ciências Biológicas que, para trabalhar a Educação Sexual nas escolas, os livros didáticos não têm se mostrado muitas vezes capazes de superar a biologia descritiva, analítica e receituária. Especialmente almeja-se uma prática pedagógica do professor integrando os conteúdos curriculares com as problemáticas sociais atuais, que parecem apenas repassar metodologias e técnicas científicas discricionárias.

A produção relacionada à temática da Educação Sexual e Formação de Professores, no Brasil, não é recente, no entanto, estas geralmente, não abordam diretamente as causas pela qual práxis docente continua sendo predominantemente a-históricas, a-críticas e a-sociais. Essa nossa reflexão emerge como necessidade de nossa práxis como docentes e licenciados em Ciências Biológicas, sempre buscando refletir sobre as dificuldades de nosso cotidiano escolar tendo em vista melhorar nossa atuação docente e atentar para que, além de ensinar os conteúdos possamos fazer com que estes possam ser analisados a partir das condições históricas e sociais, tendo em vista contribuir para a transformação da sociedade vigente, a partir de horizontes progressistas.

Enquanto se considera que, somos educadores temos como consequiência política a tarefa de desenvolver projetos educacionais que se orientam por princípios democráticos e emancipatórios, articulados com os 
interesses sociais, que podem subsidiar projetos para a construção de um ensino de ciências tomado como instrumento de compreensão da realidade histórica e para o enfrentamento organizado dos problemas sociais.

É possível ainda verificarmos que, a abordagem de Ciências no Ensino Fundamental é uma das disciplinas que despertam maior interesse dos alunos, que nesta fase da adolescência apresentam uma curiosidade aguçada, por mudanças psíquicas, físicas, sociais pelas quais passam e, conseqüentemente, necessitam de informações e respostas para suas aflições e formação de sua identidade.

As situações vivenciadas no contexto da sala de aula com os adolescentes nos levaram a se deparar com a carência de respaldos teóricos e práticos na formação dos educadores para trabalharem com a sexualidade com os alunos especialmente no ensino fundamental a qual comporta os alunos na fase transitória que dá início a adolescência. Freud afirma que a sexualidade não surge subitamente na adolescência mais se instala paulatinamente, a partir das experiências vivenciadas desde o nascimento do ser humano, mas é nesta fase segundo estudos o período de latência da sexualidade, daí a necessidade ainda maior do educador estar preparado para tratar do tema desmistificando tabus e preconceitos, e orientando sobre a sexualidade quantitativa estimulada pela mídia que muitas vezes deturpam as atitudes que seriam naturais dos adolescentes através de "apelos" consumistas da sexualidade mercantilista, fazendo com que o adolescente desenvolva uma sexualidade narcisista, individualista, instintiva que torna o corpo um mero instrumento, um objeto descartável após a satisfação de prazer desejada.

Nas duas últimas décadas o professor de Ciências tem sido um dos principais responsáveis para informar sobre a sexualidade na escola, nesse período da adolescência sendo assim os alunos canalizam neste todas as suas inquietações, no entanto o mesmo não se encontra preparado para esclarecer sobre a temática em sua totalidade.

Nunes (2003) acredita ser urgente que, agentes sociais, educadores e pais, em diferentes graus de responsabilidade informativa e formacional, 
busquem aprofundar o conhecimento sobre a Educação Sexual, para que se possam agir da forma mais consciente e esclarecedora possível, contribuindo assim para uma educação sexual que prime pela liberdade, pela sensibilidade, pelo respeito e pela igualdade. Demonstra ainda a necessidade dos educadores receberem a formação adequada para estas questões, abrir debates e criar canais de significação para que sejam capazes de abordar a sexualidade de maneira plena, em todas as suas dimensões; eróticas, subjetivas, procriativas e suas significações e conseqüências, com a devida responsabilidade e autonomia, e não apresentar uma identidade negativa e descritiva sobre o sexo e a sexualidade. Se nos esforçarmos para apresentar as razões de nossa determinação de compreender a sexualidade na trama da cultura e das relações sociais é justamente por acreditarmos que sua força humana e consequientemente pedagógica reside precisamente neste campo.

Consideramos que a escola é um dos ambientes mais oportunos e adequados para que os adolescentes sejam informados e orientados sobre sexualidade, no entanto o debate da educação sexual escolar deve ir além dos métodos anticoncepcionais e uso de preservativos e DSTs, proporcionando um debate sobre a gravidez precoce, e discernimento sobre alguns valores como: respeito mútuo, liberdade de escolha, e com isso, ofereça possibilidades ao adolescente capacidade de tomar decisões mais adequadas, desenvolvendo um compromisso consigo mesmo e com o outro.

Os conteúdos propostos pela maioria dos livros para o Ensino de Ciências sugerem uma notável ênfase na transmissão de conteúdos programáticos, que embora sejam relevantes, deveriam apresentar propostas de reflexão crítica sobre as problemáticas sociais, políticas e econômicas, para que o aluno possa estabelecer uma relação com seu cotidiano, compreender sua real significação. Propõe-se a necessidade de substituir essa concepção de ciências, baseada em taxonomias e nomenclaturas, por uma concepção de relacionar as problemáticas especialmente no que se refere à sexualidade (gravidez na adolescência, doenças sexualmente transmissíveis) com as mudanças estruturais da sociedade. Parte-se do pressuposto que para que os docentes possam superar a Orientação Sexual 
pautada na anatomia e métodos contraceptivos precisam em sua licenciatura obter o conhecimento necessário para transformar a práxis, sociedade ou cultura onde agem e atuam.

A presente pesquisa inspira-se nos referenciais conceituais $\mathrm{e}$ categóricos da análise crítico-dialética. As pesquisas crítico-dialéticas buscam transformar as situações ou fenômenos estudados, partindo sempre do resgate de sua dimensão histórica e suas possibilidades de mudança. Vislumbram ações políticas para as quais é fundamental a participação ativa do homem enquanto agente histórico, além da formação da consciência e da resistência espontânea dos sujeitos históricos nas situações de conflito.

A dimensão estrutural de nosso campo investigativo constituiu-se ao redor do resgate da identidade histórica do Curso de Ciências Biológicas, portanto a primeira etapa do estudo consistiu-se em um levantamento criterioso da literatura sobre o tema. Essa incursão foi determinada pela necessidade de compreender as matrizes culturais da significação social e ideológica de sexo e sexualidade na tradição brasileira e os marcos institucionais e políticos da formação Superior no Brasil, bem como, dentro dessa, os limites e contornos da formação do profissional de Ciências Biológicas.

Num segundo passo buscamos reconhecer as expressões materiais dessas contradições históricas, presentes na realidade educacional escolar atual. Como amostra referencial, delimitamos um campo empírico para investigação e coleta de dados, impressões, depoimentos e representações, já anteriormente referidos.

Percorremos ainda, trajetória histórica e construção social da sexualidade humana. Apresentamos os marcos teóricos filosóficos sobre a sexualidade e a passagem histórica da representação da sexualidade como tema que se deslocara do campo biológico para as ciências humanas, desde identidade biológico-reprodutiva matricial e suas legitimações com Lamarck, Mendel e Darwin à ruptura moderna com o naturalismo biológico de Havellock-Ellis e Sigmund Freud, estendendo-se até à apropriação das Ciências Humanas e Sociais das representações matriciais de sexo e 
sexualidade já legitimadas pelos estudos referenciais de Reich, Marcuse, Engels e Foucault.

Nas disposições finais do estudo apontamos algumas considerações que intentam corroborar a tese que defendemos neste estudo: de que a educação sexual escolar ainda não foi capaz de superar as matrizes e paradigmas oriundos da tradição médico-biologista. Através dos dados coletados, aqui referidos, bem como, da análise da trajetória da Sexualidade Humana e da configuração do campo institucional da Educação Sexual no Brasil constatamos que a proposta de Orientação Sexual que vem sendo desenvolvida na escola brasileira real e atual está majoritariamente alicerçada numa fundamentação biologista, dissociando-se de aspectos sociais e políticos, centralizando em conceitos e informações que apontam para os referenciais da Biologia e das biotecnologias de reprodução. Consolida-se, então, a percepção de uma concepção de sexualidade descritiva, genitalista e performática, e esta superação não pode ser feita voluntária e magicamente, pois a ampla maioria dos educadores e agentes educacionais que atuam no campo não foram preparados adequadamente para trabalhar a sexualidade em sua multiplicidade, diversidade e omnilateralidade.

\section{Considerações finais}

Constatamos que, as disciplinas pedagógicas atualmente oferecidas nos cursos de Licenciatura são insuficientes para formar os educadores sexuais emancipatórios que almejamos, sendo assim, defendemos a urgente inserção na matriz curricular da Licenciatura de uma ou mais disciplinas ou conteúdos curriculares referenciais que tratem da construção histórica da sexualidade humana desde a Biologia às Ciências Humanas, para que os educadores possam ampliar sua visão e compreensão da historicidade e da construção cultural da sexualidade. Temos consciência de que somente a inserção da disciplina nos cursos de Licenciatura não será suficiente para resolver a problemática, que está umbilicalmente ligada às questões 
históricas, políticas, religiosas, sociais, enfim culturais, mas consideramos ser este um primeiro passo no sentido de ampliar a compreensão da sexualidade e criar rupturas das quais possam surgir novos debates, embates e visões que nos permitem entender a sexualidade para além da visão reprodutiva.

Através das respostas coletadas com os educadores pudemos constatar que, a proposta de Orientação Sexual que vem sendo desenvolvida na escola está alicerçada numa fundamentação biologista, dissociando o prazer, consolidando, mesmo que inconscientemente a repressão sexual. Consideramos também a necessidade de se romper a dissociação da sexualidade apenas aos seus aspectos negativos como as DST's, gravidez não planejada, ao pecado ou como um desejo vergonhoso, que precisa ser profundamente controlado, silenciado, pois ao silenciar o prazer, a potencialidade afetiva e de realização plena, de relacionamento com o outro, do encontro, a escola e a sociedade reforçam uma sexualidade procriativa, utilitarista, banal e consumista.

A atual forma como a sexualidade humana tem sido abordada apenas enfatizando a visão biologista reforça ainda uma sexualidade genitalista, concentrando-se na anatomia (pênis, vagina, órgãos sexuais) como se a sexualidade e o prazer se concentrasse apenas nos órgãos genitais. Sendo assim, defendemos a incorporação na formação do Licenciado em Biologia de uma disciplina que trate da construção histórica da sexualidade humana desde a Biologia às Ciências Humanas e da Saúde, promovendo uma ampliação da compreensão da historicidade e da construção social da sexualidade, com uma maior atenção à cultura, às políticas e às cenas contemporâneas, cujos produtos midiáticos, sejam televisivos, cinematográficos, fotográficos ou escritos; ou nas ondas da internet têm produzido "significações" que influem diretamente na forma com que a sexualidade vem sendo vivida. Possibilitando então, aos educadores a aquisição de conhecimentos e segurança para conduzir a educação sexual nas escolas. 
Este estudo levou-nos a constatação também de que as disciplinas pedagógicas atualmente oferecidas nos cursos de Licenciatura são insuficientes para formar educadores sexuais. As disciplinas específicas são fundamentais para a formação de conhecimentos biológicos necessários a atuação profissional do biólogo/bacharel, mas não dão conta de atender, também, a formação docente, pois atual matriz curricular dos cursos de graduação em Ciências Biológicas mostra claramente que as disciplinas oferecidas privilegiam a formação do Bacharel, deixando lacunas pedagógicas na formação do Licenciado em Ciências Biológicas. Para tanto há que mudar primeiro a ênfase dos cursos, e a concepção dos professores que atuam nesta área.

Temos ainda, que ter a clareza que, a ação educativa não se efetua apenas no âmbito escolar, mas também, na escola. Os bacharéis em biologia ocupam também espaços onde necessitam desenvolver trabalhos educativos na área da Educação Ambiental. Portanto vislumbramos a necessidade tanto do Bacharel em Ciências Biológicas conhecer o campo educacional, como os Licenciados em Ciências Biológicas ter conhecimento das especificidades biológicas, pois ambos os profissionais necessitam desenvolver ações e intervenções educativas/pedagógicas.

Queremos explicitar que nesta pesquisa nossa defesa foi por uma educação sexual capaz de superar as meras informações biológicas e médico-higienistas. Consideramos a necessidade de se construir uma política pedagógica para a educação sexual escolar. Temos clareza de que isto não será capaz de romper totalmente com a visão de sexualidade que estamos condicionados há séculos, porém pode minimizar vivências sexuais repressivas e preconceituosas, porém responsáveis e afetivas.

Ressaltamos que, não estamos excluindo a importância da compreensão biológica da sexualidade em contraposição às ciências sociais e humanas, mas entendemos que, para uma compreensão plena da sexualidade e suas potencialidades subjetivas, precisamos homogeneizar as abordagens existentes, para possibilitar a superação da repressão, dos preconceitos e das resistências e impasses que permeiam o campo da 
sexualidade humana. Por isso, neste estudo nos esforçamos na aproximação e compreensão teórica e histórica das diferentes possibilidades de construção da sexualidade seja individual, grupal ou social nos diferentes momentos histórico-culturais, permeados inicialmente pela visão reprodutiva e biológica, pelos dogmas religiosos, pelo "silenciamento", pelas ideologias, pelas formas de idealizadas de afeto (como o ideal do amor romântico limitando e vinculando a sexualidade apenas ao casamento).

Buscamos mostrar que, a sexualidade humana edificou-se nas bases dos dogmatismos, marcada pelo lugar que a reprodução e a família ocupam na sociedade capitalista, no sistema social e nos meios de produção que resumem o corpo à força produtiva do capital e, que ainda hoje, ainda que a sexualidade tenha sido banalizada, permissiva e liberalizada ainda não conseguimos compreender e viver plenamente a sexualidade, por estarmos fundamentalmente arraigados pelas limitações que potencial de repressão da sociedade exerce sobre nossa subjetividade e nossa trajetória sexual.

Através desta pesquisa compreendemos que, a educação sexual escolar brasileira tem sua origens na concepção médico-higienista-biologista e religiosa, o que se estende até os dias de hoje, principalmente com o advento da Aids, e esperamos ter consoguida evidenciar a necessidade urgente da formação de professores desde a Licenciatura, estendendo-se posteriormente em cursos de formação continuada.

Constatamos que a formação do Licenciado é anacrônica, insuficiente para trabalhar a sexualidade, apresentando uma exigüidade de informações. O Currículo como pudemos verificar no decorrer do estudo possui uma identidade biologista, fossilizada e viabilizada no século XIX, ou seja, ou seja ainda pautada apenas no caráter biologizante, sem avanços significativos capazes de ampliar as pesquisas empiristas e darwinistas.

Desde Mendel, Darwin e Lamarck que, certamente são o marco significativo para a compreensão biológica da nossa sexualidade, a biologia ainda não conseguiu superar em suas grades curriculares o anacronismo biológico; a conceituação de sexo e sexualidade ainda continua meramente biológica, culminando num reducionismo epistemológico, ou seja, o biólogo 
não se apropriou da visão psicanalítica das Ciências Humanas, configurando as Ciências Biológicas com uma área fechada, hermética (hermetismo). Se fizermos um levantamento das pesquisas produzidas na área das Ciências Biologias é possível verificarmos que falta pesquisas e articulações teóricas com outras áreas, ou seja, as pesquisas no campo de sexo e sexualidade se caracterizam em sua grande maioria, reducionistamente dentro da biologia, o que mostra a falta de consciência de muitos professores sobre a importância da sexualidade de maneira integral e também a insensibilidade de alguns docentes sobre a questão da sexualidade na maioria das vezes reduzindo a fala sobre sexualidade na escola às DST's e métodos anticoncepcionais.

É evidente que, isto se dá, por alguns motivos como:

- A dificuldade pessoal de lidar com o tema (de lidar com a própria sexualidade, sem corporeidade), fruto da forma como foram educados, condicionados a viver e pensar a sexualidade, seja pela família, pela escola, pela religião, enfim pelos condiocionamentos sociais

- Realidade da Docência (quadro atual, condições de trabalho impedem que os professores desenvolvam sua própria percepção de sexualidade)

- Insuficiência dos Parâmetros Curriculares Nacionais para a área e de materiais didáticos sobre sexualidade

- Profissional semi-formado, semi-habilitado, semi-preparado para compreender e viver a sexualidade.

Pelas respostas coletadas na pesquisa de campo é evidente que os professores/educadores, não se sentem preparados para atuar com a Educação Sexual, o que apenas reafirma nossa tese sobre a falta e importância de sua formação para trabalhar com a temática, e ainda a necessidade de inclusão de uma disciplina de Educação Sexual nos cursos de Licenciatura, bem como do investimento governamental em cursos formação continuada que possibilite aos docentes a rever de seus conceitos e a ampliar seus conhecimentos sobre sexualidade. Para que isto se efetive, faz-se necessário uma reivindicação coletiva, tanto junto às universidades quanto às instâncias responsáveis pela coordenação do ensino em suas 
diversas esferas, para que sejam estabelecidas políticas para que tal se concretize.

Por considerarmos a sexualidade como um dos núcleos fundamentais da personalidade humana, integrando plenamente o desenvolvimento do ser humano, não se reduzindo apenas em momentos e comportamentos, e que viver a sexualidade com liberdade, responsabilidade afetiva e de forma saudável nos torna mais humanizados, realizados e dispostos para a vida, entendemos o quão importante é que essa temática seja tratada de maneira natural e debatida abertamente no ambiente educacional. No entanto, uma das constatações de nossos estudo aponta fortemente para as lacunas na formação docente quanto o assunto é Educação Sexual, o que necessita urgentemente ser enfrentada, para que os educadores tenham formação teórica para superar as meras, embora também importantes informações biológicas. Para tanto sugerimos a inserção de disciplinas multidisciplinares obrigatórias na grade curricular dos cursos de Licenciatura. Destacamos também a necessidade de realizações de cursos de formação, eventos e congressos que abordem a sexualidade de maneira global.

Temos plena consciência, de que é difícil superar os objetivos reducionistas das próprias diretrizes oficiais de políticas de saúde sexual (prevenção da AIDS e DST’s) entre os adolescentes, bem como, sabemos que há inúmeras resistências dentro do próprio espaço escolar e social para debatermos a sexualidade.

Destacamos ainda, a necessidade de projetos de Educação Sexual que, envolvam a família, que não está preparada para dialogar sobre a sexualidade e abordando esta, quando o faz, de forma repressiva, incoerente e inadequada. A escola é subsidiária da família, portanto os pais devem ter consciência da importância e da necessidade de abrir um espaço de diálogo com os filhos, fornecendo informações sobre a sexualidade seja através do diálogo, de livros de educação sexual, vídeos e/ou reflexões sobre filmes, programas televisivos, novelas, etc, conversas do dia-a-dia sobre valores, sobre comportamentos que devem ser adotados, sobre o que é ou não adequado, sobre o que deve ser rejeitado, etc, desenvolvendo atitudes, 
valores, capacidade de discernimento e criticidade em relação ao próprio comportamento e de outros para que possam viver uma sexualidade com liberdade, responsabilidade e naturalidade.

Espera-se que, a Educação Sexual Emancipatória nas escolas possa ser delineada, procurando contribuir para outra perspectiva de Educação capaz de atentar efetivamente para a compreensão da vida em sua totalidade. Convidamos novos sujeitos e diferentes interlocutores, para essa ousada aventura crítica e interpretativa, a partir de leituras e pesquisas criteriosas, a abrir novos caminhos nas Ciências Biológicas e na Educação, a partir das balizadas questões da Filosofia e suas desafiadoras bases e expressões.

\section{Referências}

BERNARDO, M. V. C. Como a universidade potencializa a educação. Didática, São Paulo, v.22/23, p.83-88, 1986.

NUNES, C. A. Desvendando a Sexualidade. Campinas, SP: Papirus, 1987.

NUNES, C. A. Filosofia, Sexualidade e Educação: as relações entre os pressupostos ético-sociais e histórico-culturais presentes nas abordagens institucionais sobre a educação sexual escolar (Tese de Doutorado) Campinas: FE-UNICAMP, 1996.

NUNES, C. A. Educar para a Emancipação. Florianópolis, SC: Sophos, 2003. 